\title{
Performance of a diesel engine running on mixed biofuels with the addition of gasoline
}

\author{
Vladimir Markov ${ }^{1}$, Vyacheslav Kamaltdinov², Larisa Bykovskaya ${ }^{1}$, and Bowen Sa ${ }^{1, *}$ \\ ${ }^{1}$ Bauman Moscow State Technical University, Moscow, Russian \\ ${ }^{2}$ South Ural State University, Chelyabinsk, Russia
}

\begin{abstract}
The significance of the paper is confirmed by the need to replace petroleum motor fuels with fuels produced from alternative energy sources. Biofuels derived from various vegetable resources are considered as promising alternative fuels for diesel engines. These fuels offer significant advantages with respect to the renewability of their raw materials and good emission performances when burned in ICEs. The main problem of using vegetable oils as biofuels for diesel engines is their high viscosity. This problem can be resolved by using mixed biofuels with the addition of gasoline. The analysis of physicochemical properties of petroleum diesel fuel (DF) and mixed biofuels containing petroleum DF, rapeseed oil (RO) and AI-80 automotive gasoline was conducted. Experimental studies of the D-245.12S diesel fuelled with these mixed fuels were carried out. The mixed fuels were prepared from $80 \% \mathrm{DF}+20 \% \mathrm{RO}$, from $75 \% \mathrm{DF}+20 \% \mathrm{RO}+5 \% \mathrm{AI}-80$, and from $70 \% \mathrm{DF}+20 \% \mathrm{RO}+10 \% \mathrm{AI}-80$. It was shown that the addition of gasoline to mixed biofuels could improve two main toxicity indicators of exhaust gases exhaust gases smoke and emissions of nitrogen oxides. The best emission performance was achieved for the mixture of $70 \% \mathrm{DF}, 20 \% \mathrm{RO}$ and $10 \% \mathrm{AI}-80$. When the diesel engine was switched from the mixture of $80 \% \mathrm{DF}$ and $20 \% \mathrm{RO}$ to the mixture of $70 \% \mathrm{DF}, 20 \% \mathrm{RO}$ and $10 \% \mathrm{AI}-80$, the exhaust gases smoke at maximum torque mode decreased from 17.5 to $14.5 \%$ on the Hartridge scale, i.e. by $17.1 \%$. The specific emissions of nitrogen oxides decreased from 6.559 to $6.154 \mathrm{~g} /(\mathrm{kW} \cdot \mathrm{h})$, i.e. by $6.2 \%$.
\end{abstract}

\section{Introduction}

The prospects of using biofuels obtained from vegetable oils in diesel engines have been discussed in numerous studies [1-4]. The use of biofuels based on vegetable oils enables not only to ensure the replacement of petroleum fuels with fuels obtained from renewable raw materials, but also to improve the emission performance of diesel engines [5-8]. Widespread introduction of such biofuels in transport, agriculture, and other sectors of economy is constrained by a number of factors, one of which is the difference in their physicochemical properties from that of traditional petroleum fuels [9-12]. Mixing of several dissimilar components is considered as one of the most effective ways to ensure the required properties of these biofuels. The best results are obtained by mixing several components at once, i.e. the use of multi-component mixed biofuels [13-18]. An important feature of vegetable oils is the ability to mix it in any proportions with most organic solvents (including petroleum products including gasoline, kerosene and diesel fuel). This feature allows obtaining multi-component biofuels with specified physico-chemical properties by mixing various components in the required proportions.
It should be noted that the maximum approximation of the indicated physical properties of mixed biofuels to the properties of petroleum diesel fuel can be achieved by adding light petroleum or alternative fuels (light individual hydrocarbons, gas condensates, ethanol, dimethyl ether) to biofuels derived from vegetable oils [19-21]. The use of automotive gasolines as a lowviscosity additive to mixed biofuels containing petroleum diesel fuel and vegetable oils is a promising way. The efficiency of diesel engines when adding gasoline to fuels with a heavier fractional composition has already been confirmed by a number of studies of diesel engines that work not only with gasoline additives in diesel fuel, but also with pure gasoline [22, 23].

The autotractor diesel operating on multi-component mixed biofuels obtained by adding petroleum fuel with a light fractional composition (gasoline) to the mixture of petroleum diesel fuel (DF) and rapeseed oil (RO) was selected as the object of the present study. This additive provides a significant reduction in viscosity of multicomponent biofuels obtained as a result of such mixing. AI-80 gasoline, which has a relatively high (compared with other gasolines) cetane number $(\mathrm{CN}=20)$ was selected as the low-viscosity fuel. Table 1 shows the physico-chemical properties of the studied multi-

\footnotetext{
* Corresponding author: bowensa@yandex.ru
} 
component mixed biofuels with the addition of gasoline, and the properties of the individual components of these mixtures. These data confirm the possibility of approximating the characteristics of multi-component mixed biofuels to similar characteristics of petroleum diesel fuel. In particular, the kinematic viscosity of the $\mathrm{W}$ (winter) grade diesel fuel considered below at $\mathrm{t}=20^{\circ} \mathrm{C}$ is $v=2.37 \mathrm{~mm}^{2} / \mathrm{s}$. The corresponding kinematic viscosities of the mixture of $75 \% \mathrm{DF}, 20 \% \mathrm{RO}, 5 \% \mathrm{AI}-$ 80 and the mixture of $70 \%$ DF, 20\% RO, 10\% AI-80 were 6.1 and $3.6 \mathrm{~mm}^{2} / \mathrm{s}$, respectively. This practically fits into the allowable range of viscosity change for petroleum DF of the $\mathrm{S}$ (summer) grade according to GOST $305-2013$, equal to 3.0 to $6.0 \mathrm{~mm}^{2} / \mathrm{s}$ (Table 1) [24]. Thus, the presence of AI-80 gasoline with fractions boiling range from $30-40$ to $200-215{ }^{\circ} \mathrm{C}$, density from 725 to $780 \mathrm{~kg} / \mathrm{m}^{2}$ and low viscosity (up to $0.78 \mathrm{~mm}^{2} / \mathrm{s}$ ) [25] in the studied multi-component biofuels, allowed to provide the required viscosity characteristics of these fuels. The purpose of this study is to determine the characteristics of a diesel engine running on these mixed biofuels with the addition of gasoline.

Table 1. Physico-chemical properties of the investigated fuels

\begin{tabular}{|c|c|c|c|c|c|c|}
\hline \multirow[b]{2}{*}{$\begin{array}{l}\text { Physico- } \\
\text { chemical } \\
\text { properties }\end{array}$} & \multicolumn{6}{|c|}{ Fuels } \\
\hline & DF & RO & AI-80 & $\begin{array}{c}80 \% \\
\text { DF } \\
\text { and } \\
20 \% \\
\text { RO }\end{array}$ & $\begin{array}{c}75 \% \\
\text { DF, } \\
20 \% \\
\text { RO } \\
\text { and } \\
5 \% \\
\text { AI-80 }\end{array}$ & $\begin{array}{c}70 \% \\
\text { DF, } \\
20 \% \\
\text { RO } \\
\text { and } \\
10 \% \\
\text { AI-80 }\end{array}$ \\
\hline $\begin{array}{c}\text { Density at } \\
20^{\circ} \mathrm{C}, \\
\mathrm{kg} / \mathrm{m}^{3}\end{array}$ & 805 & 913 & 756 & 848 & 824 & 823 \\
\hline $\begin{array}{c}\text { Kinematic } \\
\text { viscosity } \\
\text { at } 20^{\circ} \mathrm{C} \text {, } \\
\mathrm{mm}^{2} / \mathrm{s}\end{array}$ & 2.37 & 75.00 & 0.73 & 9.00 & 6.10 & 3.60 \\
\hline $\begin{array}{c}\text { The lower } \\
\text { heating } \\
\text { value, } \\
\mathrm{kJ} / \mathrm{kg}\end{array}$ & 42500 & 37300 & 44000 & 41500 & 41500 & 41600 \\
\hline $\begin{array}{l}\text { Cetane } \\
\text { number }\end{array}$ & 45 & 36 & 20 & 43 & 40 & 36 \\
\hline
\end{tabular}

Note: the indicated percentage is the volume percentage of components in the mixture; DF is diesel fuel (GOST 3052013); RO is rapeseed oil (GOST 31759-2012); AI-80 is gasoline (GOST 32513-2013)

\section{Methods}

\subsection{Experimental setup}

The influence of composition of multi-component biofuels on the indicators of fuel economy and toxicity of exhaust gases (EG) was assessed using the results of experimental studies carried out on an experimental setup based on the D-245.12S (4 CHN 11/12.5) diesel engine produced by the Minsk Motor Plant. The experimental setup was described in the work [13]. The $\mathrm{D}-245.12 \mathrm{~S}$ diesel engine had a fuel system that included Motorpal high-pressure fuel pump of the PP4M10U1f type with the plunger diameter $\mathrm{d}_{\mathrm{pl}}=10 \mathrm{~mm}$ and the total plunger stroke $h_{\mathrm{pl}}=10 \mathrm{~mm}$, high pressure fuel lines with length $\mathrm{L}_{\mathrm{f}}=540 \mathrm{~mm}$ and FDM-22 injectors, which were adjusted to the start injection pressure $p_{i n j}=21.0 \mathrm{MPa}$. During testing, the installation angle of advance of fuel injection equals to $\theta=13^{\circ}$ of crankshaft rotation to top dead center (TDC) and the position of the stop of maximum fuel supply remained unchanged.

The experimental setup was equipped with a set of necessary measuring equipment. The engine speed was measured by a speedometer with sensors mounted on the flywheel of the engine crankshaft. The measurement range of speedometer is $0 \sim 5000 \mathrm{~min}^{-1}$, and the measurement error is $\pm 5 \mathrm{~min}^{-1}$ (relative measurement error is $\pm 0.1 \%$ ). Air and fuel consumption were measured by flowmeters. The measurement range of air flowmeter is $0 \sim 1000 \mathrm{~kg} / \mathrm{h}$, and the measurement error is $\pm 10 \mathrm{~kg} / \mathrm{h}$ (relative measurement error is $\pm 1 \%$ ). The measurement range of fuel flowmeter is $0 \sim 40 \mathrm{~kg} / \mathrm{h}$, and the measurement error is $\pm 0.1 \mathrm{~kg} / \mathrm{h}$ (relative measurement error is $\pm 0.25 \%$ ). Exhaust smoke opacity was measured by using a MK-3 smoke meter from Hartridge (United Kingdom) within the range of 0 $100 \%$ with a measurement error of $\pm 1 \%$. A Yanaco SAE-7532 gas analyzer was used to determine the concentrations of nitrogen oxides $\left(\mathrm{NO}_{\mathrm{X}}\right)$, carbon monoxide (CO) and unburned hydrocarbons $(\mathrm{CHx})$ in exhaust gases. The measurement error of nitrogen oxide

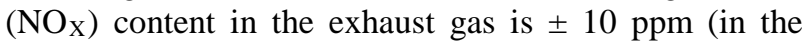
concentration range from 1000 to $4000 \mathrm{ppm}$ ). For carbon monoxide (CO) and unburned hydrocarbons ( $\mathrm{CHx}$ ), these errors are $\pm 3 \%$ in the concentrations range from 0 to $5 \%$ and $\pm 10 \mathrm{ppm}$ in the concentrations range from 0 to 200 ppm, respectively.

\subsection{Experimental procedures}

At the first stage of experimental studies, the diesel engine was tested under external speed characteristic (ESC) modes using a mixture of $80 \%$ DF and $20 \%$ RO, as well as using the indicated multi-component mixtures of petroleum DF, RO and AI-80 gasoline. At the second stage, the engine was tested on these fuels in the 13mode test cycle of ECE R49 of UNECE Regulation No.49 (Fig. 1). The integral specific mass emissions of harmful substances in the 13-mode cycle were calculated ( $\mathrm{e}_{\mathrm{NOx}}, \mathrm{e}_{\mathrm{CO}}, \mathrm{e}_{\mathrm{CHx}}$, respectively) based on the experimental results by using the generally accepted methods. When assessing the integral toxicity of the engine exhaust gases in such cycle modes, the concentrations of harmful substances in the exhaust gas $\left(\mathrm{C}_{\mathrm{NOx}}, \mathrm{C}_{\mathrm{CO}}, \mathrm{C}_{\mathrm{CHx}}\right)$ were determined for each mode and their hourly mass emissions ( $\left.E_{\mathrm{NOx}}, E_{\mathrm{CO}}, E_{\mathrm{CHx}}\right)$ were calculated. The obtained values of harmful emissions are summed over the entire cycle for each component (taking into account the weight coefficients $K_{\mathrm{i}}$, which reflect the time fraction of each mode). Then, the specific mass emissions of harmful substances were obtained by dividing the sum value by the conditional average diesel power for the test cycle $\Sigma\left(N_{e i} \cdot K_{i}\right)$, i.e. the specific mass emissions of harmful substances were determined by formulas [13]: 


$$
\begin{aligned}
& e_{\mathrm{NOx}}=\frac{\sum_{i=1}^{13} E_{\mathrm{NOx} i} \cdot K_{i}}{\sum_{i=1}^{13} N_{e i} \cdot K_{i}}, \\
& e_{\mathrm{CO}}=\frac{\sum_{i=1}^{13} E_{\mathrm{CO} i} \cdot K_{i}}{\sum_{i=1}^{13} N_{e i} \cdot K_{i}}, \\
& e_{\mathrm{CHx}}=\frac{\sum_{i=1}^{13} E_{\mathrm{CHx} i} \cdot K_{i}}{\sum_{i=1}^{13} N_{e i} \cdot K_{i}} .
\end{aligned}
$$

Using the hourly fuel consumption $G_{f}$ obtained at each of the modes of the 13-mode cycle, the integral (conditional) values of specific effective fuel consumption $g_{\mathrm{e}_{-} \text {cond }}$ and the conditional effective diesel efficiency $\eta_{\mathrm{e} \_ \text {cond }}$ were determined for these modes using the dependencies [13]

$$
\begin{array}{r}
g_{\text {e_cond }}=\frac{\sum_{i=1}^{13} G_{\mathrm{T} i} \cdot K_{i}}{\sum_{i=1}^{13} N_{e i} \cdot K_{i}}, \\
\eta_{\text {e_cond }}=\frac{3600}{H_{U} \cdot g_{\text {e_cond }}},
\end{array}
$$

where $H_{U}$ is the fuel lower heating value of fuel, $\mathrm{kJ} / \mathrm{kg}$. The results of these calculations are shown in Fig. 2 and 3.

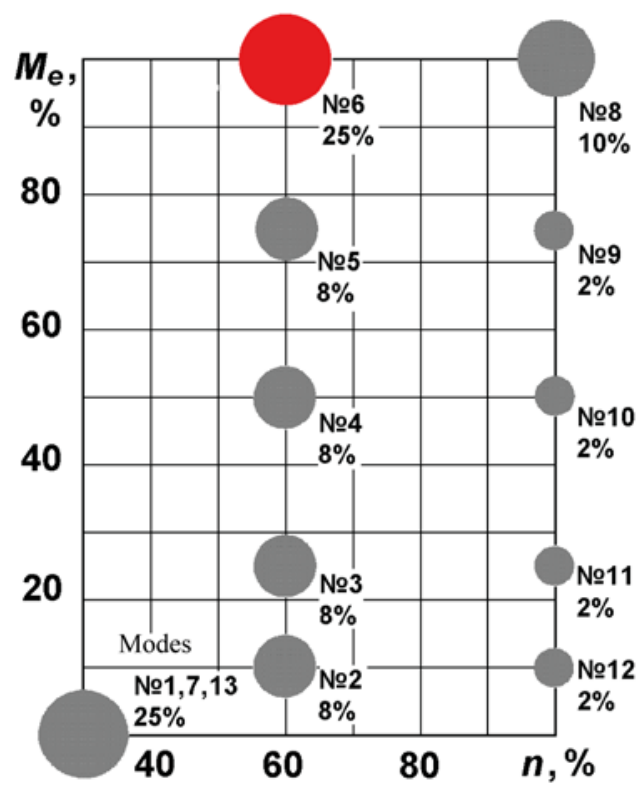

Fig. 1. The European 13-mode steady-state diesel engine test cycle (ECE R49) used for emission testing of engines of middle and heavy duty vehicles - with a total mass above 3.5 tons. Near each mode indicated by a circle, its number is shown and the time-share of each mode is shown in percent of total operating time; $n$ - engine speed characterizing the speed operating condition; $M_{\mathrm{e}}$ - torque on the crankshaft characterizing the load operating condition; the maximum torque condition is highlighted in red

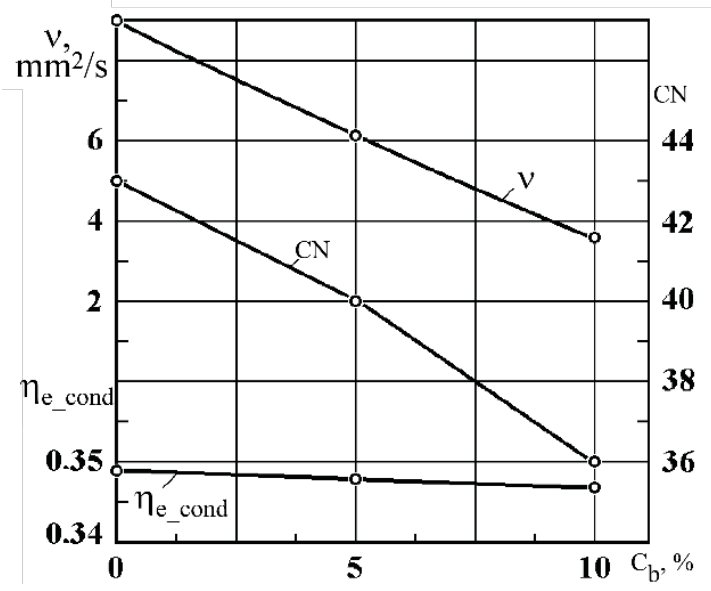

Fig. 2. Relationship between viscosity $v$, cetane number and conditional effective diesel efficiency $\eta_{\mathrm{e} \_}$cond and the AI-80 gasoline content $C_{\mathrm{b}}$ in mixed biofuel

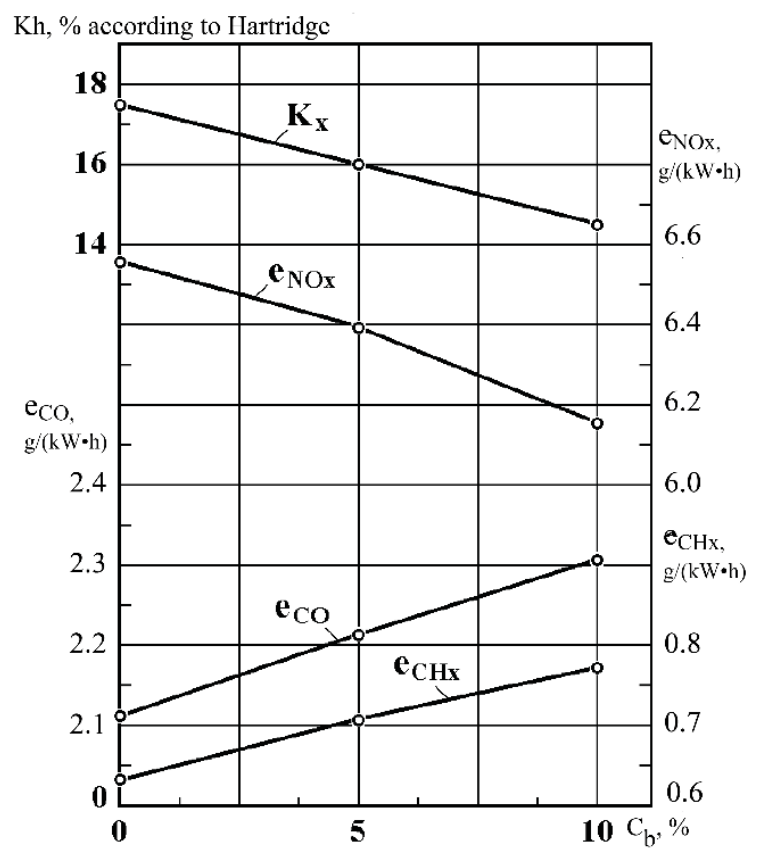

Fig. 3. Relationship between exhaust gases smoke opacity $K_{\mathrm{h}}$ in the maximum torque condition of ESC (mode № 6 in Fig. 1), specific mass emissions of harmful substances in the modes of the 13-mode cycle of ECE R49 (nitrogen oxides CNOx, carbon monoxide $\mathrm{C}_{\mathrm{CO}}$, unburned hydrocarbons $\mathrm{C}_{\mathrm{CH}}$ ) and the AI-80 gasoline content $C_{\mathrm{b}}$ in mixed biofuel

\section{Results and Discussion}

The main results of these tests are presented in Fig. 2 and Fig. 3. The results of experimental and computational studies of the diesel engine running on mixed biofuels with the addition of gasoline confirmed the efficiency of using these multi-component fuels in diesel engines. The physico-chemical properties of these fuels are quite close to the properties of petroleum diesel fuel according to GOST 305-2013 (see Table 1 and Fig. 2). Thus, the kinematic viscosity of the investigated multi-component mixtures varied from 3.6 to $6.1 \mathrm{~mm}^{2} / \mathrm{s}$ (the permissible range of viscosity change for pertoleum DF of S grade according to GOST $305-2013$ is $3.0-6.0 \mathrm{~mm}^{2} / \mathrm{s}$ ). The cetane number of these mixed fuels varies from 36 to 40 
(for petroleum DF it equals to 45). The lower heating value of the investigated multi-component fuels was 41.5-41.6 MJ/kg (for petroleum DF it is $42.5 \mathrm{MJ} / \mathrm{kg}$ ). The obtained conditional effective diesel efficiency $\eta_{\mathrm{e} \_c o n d}$ for the investigated multi-component fuels were $0.347-0.348$. These indicators slightly differ from that obtained during the operation of the investigated diesel engine with petroleum DF (by a value of not more than $1-2 \%)$ [13]. All this indicates the possibility of efficient use of these multi-component biofuels in diesel engines.

It should be noted that the addition of gasoline to the investigated biofuels favorably affects two main emission indicators of diesel exhaust gases, namely smoke opacity $K_{\mathrm{h}}$ (carbon C) and nitrogen oxides $\mathrm{e}_{\mathrm{NOx}}$ (Fig. 3). When converting a diesel engine from a mixture of $80 \%$ DF and $20 \%$ RO to multi-component biofuels, the exhaust gases smoke opacity $K_{\mathrm{h}}$ at the most critical operating condition of maximum ESC torque (mode № 6 in Fig. 1) decreased from 17.5 to $14.5 \%$ on the Hartridge scale (for a mixture of $70 \%$ DF, $20 \%$ RO and $10 \%$ AI80 ), i.e. by $17.1 \%$. This is driven by the lower content of heavy petroleum fractions in multi-component mixed biofuels with the addition of gasoline. At the same time, the specific mass emissions of nitrogen oxides $\mathrm{e}_{\mathrm{NOx}}$ decreased from 6.559 to $6.154 \mathrm{~g} /(\mathrm{kW} \cdot \mathrm{h})$, i.e. by $6.2 \%$. Such a decrease in the emission of nitrogen oxides is due to some deterioration in the quality of the working process in the presence of gasoline in mixed biofuels.

In the studied content range of AI-80 gasoline in the mixed biofuel $C_{\mathrm{b}}$ (from 0 to $10 \%$ by volume), emissions of carbon monoxide e e increased (from 2.123 to 2.313 $\mathrm{g} /(\mathrm{kW} \cdot \mathrm{h})$, i.e. by $8.9 \%)$ and emissions of unburned hydrocarbons $\mathrm{e}_{\mathrm{CHx}}$ also increased (from 0.665 to 0.772 $\mathrm{g} /(\mathrm{kW} \cdot \mathrm{h})$, i.e. by $16.1 \%)$. This is explained by the aforementioned deterioration in the quality of the working process in the presence of gasoline in mixed biofuels, as well as the presence of light gasoline fractions in multi-component mixed biofuels that do not completely burn and are released from the exhaust gas into the atmosphere. But, it should be noted that the toxicological significance of carbon monoxide and unburned hydrocarbons is an order of magnitude lower than that of nitrogen oxides and soot particles (exhaust gases smoke opacity) [7]. In addition, the emissions of these harmful substances can be effectively reduced by using neutralizers, with which modern cars and agricultural machinery are equipped [7].

Taking into consideration this circumstance, it can be concluded that among the investigated multi-component mixed biofuels, the biofuel containing 70\% DF, 20\% $\mathrm{RO}$, and $10 \% \mathrm{AI}-80$ are optimal. When operating on this fuel, the smallest emissions of the two main harmful substances of the exhaust gases, namely smoke $K_{\mathrm{h}}$ (carbon C) and nitrogen oxides $\mathrm{e}_{\mathrm{NOx}}$ were noted.

\section{Conclusion}

The research results showed that the addition of a small amount of AI-80 gasoline to the mixture of petroleum diesel fuel and rapeseed oil made it possible to approximate the properties of biofuels with vegetable oils to the properties of traditional petroleum DF. This facilitates the organization of fuel injection, fuel atomization, mixture formation and subsequent combustion. In addition, the adaptation of engines to work on multi-component biofuels simplifies the supply of engine fuel for automobiles and agricultural machinery. The addition of a small amount of AI-80 gasoline to a mixture of petroleum diesel fuel and rapeseed oil allowed improving the engine emission performances.

The mixed biofuel of 70\% DF, 20\% RO and 10\% AI80 has the best environmental qualities. When operating on this fuel, the smallest emissions of the two main harmful substances from the exhaust gases namely smoke $K_{\mathrm{h}}$ (carbon C) and nitrogen oxides $\mathrm{e}_{\mathrm{NOx}}$ were noted. The conditional effective efficiency of the diesel engine $\eta_{e_{-} \text {cond }}$ in the modes of the 13-mode test cycle was less dependent on the type of fuel used.

\section{References}

1. V. L'otko, V.N. Lukanin, A.S. Khachiyan, The use of alternative fuels in internal combustion engines (MADI, Moscow, 2000)

2.I.P. Vasiliev, The influence of fuels of vegetable origin on the environmental and economic indicators of diesel (Volodymyr Dahl EUNU, Lugansk, 2009)

3. V.F. Fedorenko, N.T. Sorokin, D.S. Buklagin, N.P. Mishurov, V.S. Tikhonravov, Innovative development of alternative energy. Part 1 (FGNU Rosinformagroteh, Moscow, 2010)

4. P.R. Vallejo Maldonado, Energy-saving technologies and alternative energy (RUDN, Moscow, 2008)

5. N.N. Patrahaltsev, Improving the economic and environmental qualities of internal combustion engines through the use of alternative fuels (RUDN, Moscow, 2008)

6. S.V. Gusakov, Prospects for the use of alternative fuels from renewable sources in diesel engines (RUDN, Moscow, 2008)

7. V.A. Markov, R.M. Bashirov, I.I. Gabitov, Toxicity of diesel exhaust gases (BMSTU, Moscow, 2002)

8. V.I. Erokhov, The toxicity of modern cars. Methods and means of reducing harmful emissions into the atmosphere (Forum, Moscow, 2013)

9. R.Sh. Kuliev, F.R. Shirinov, F.A. Kuliev, Chem. Technol. Fuels oils 4, 36 (1999)

10. S.N. Devyanin, A.A. Putan, Selskiy Mech. 9, 28 (2009)

11. S.P. Kulmanakov, R.S. Semenov, Polzunovsky Vestn. 4, 55 (2007)

12. V.A. Markov, V.G. Kamaltdinov, S.S. Loboda, Procedia Eng. 150, 225 (2016)

13. V.A. Markov, S.N. Devyanin, V.G. Semenov, V.V. Bagrov, S.A. Zykov, Motor fuels produced from vegetable oils (Lambert Academic, Riga, 2019) 
14. W.-J. Lee, Y.-C. Liu, F. K. Mwangi, W.-H. Chen, S.-L. Lin, Y. Fukushima, C.-N. Liao, L.-C. Wang, Energy, 36, 5591 (2011)

15. S. Manigandan, P. Gunasekar, J. Devipriya, S. Nithya, Fuel, 235, 723 (2019)

16. S. Vellaiyan, A. Subbiah, P. Chockalingam, Fuel, 237, 1013 (2019)

17. M.A. Ghadikolaei, C.S. Cheung, K.F. Yung, , Fuel, 235,288 (2019)

18. A.G. Govorun, M.V. Pavlovsky, in Int. Sci. Tech. Conf. AAI "Automobile Tractor-Building Russ. Dev. Priorities Train. Spec, (Moscow, 2016), pp. 80-84

19. N.N. Patrahaltsev, A.A. Savastenko, The use in diesel engines of alternative fuels, as additives to the main ones (Legion-Avtodata, Moscow, 2014)

20. H.B. Rokni, J.D. Moore, A. Gupta, M.A.M. Hugh, M. Gavaises, Fuel, 241,1203 (2019)

21. M. Lapuerta, J. Rodriguez-Fernandez, D. Fernandez-Rodriguez, R. Patino-Camino, Fuel, 199, 332 (2017)

22. V.A. Markov, S.I. Kozlov, Fuel and fuel supply of multi-fuel and gas-diesel engines (BMSTU, Moscow, 2000)

23. S. Zhong, M. L. Wyszynski, A. Megaritis, D. Yap, H. Xu, (2005)

24. Diesel Fuels. Technical Conditions (Standartinform, Moscow, 2014)

25. Motor Fuels. Unleaded Gasoline. Technical Conditions (Standartinform, Moscow, 2014) 